\title{
AISI 304 Welding Fracture Resistance by a Charpy Impact Test with a High Speed Sampling Rate
}

\author{
Bambang Riyanta ${ }^{1,2, *}$ (D) I. N. G. Wardana ${ }^{2}$, Yudy Surya Irawan ${ }^{2}$ and Moch. Agus Choiron ${ }^{2}$ \\ 1 Department of Mechanical Engineering, Muhammadiyah University of Yogyakarta, \\ Bantul Yogyakarta 55183, Indonesia \\ 2 Department of Mechanical Engineering, Brawijaya University, Malang 65145, Indonesia; \\ wardana@ub.ac.id (I.N.G.W.); yudysir@ub.ac.id (Y.S.I.); agus_choiron@ub.ac.id (M.A.C.) \\ * Correspondence: bambangriyanta@umy.ac.id; Tel.: +62-0274-375798
}

Received: 24 October 2017; Accepted: 29 November 2017; Published: 5 December 2017

\begin{abstract}
The purpose of this study was to evaluate fracture resistance in AISI 304. The J-R curve was constructed from data, which resulted from an impact test by Charpy Impact machine equipped with high-speed sampling rate data acquisition equipment. The critical values of fracture resistance in fusion zones (FZ), high temperature heat affected zones (HTHAZ), low temperature heat affected zones (LTHAZ) and unaffected base metals (UBM) were obtained by calculation methods using some formulas and by graphical methods. Laboratory experiments demonstrated the relationships among the values of energy absorption along the impact test with the obstruction of dislocation movement due to the presence of chromium interstitial solute in all zones and chromium rich carbide precipitates in fusion zones and heat affected zones.
\end{abstract}

Keywords: fracture resistance; Charpy impact test; J-R curve; dislocation; precipitate

\section{Introduction}

The critical values of such fracture parameters are known as fracture resistance. Fracture resistance is the ability of a ductile material to accept load or deform plastically and resist fractures in the presence of cracks based on the Elastic Plastic Fracture Mechanics (EPFM) approach [1-3]. J-R curves have been widely used to measure the fracture resistance, and their determination has been standardized in ASTM E 1820, which combines the testing and analysis procedures of E 813 and E 1152. The recommended specimen in the standard were fatigue pre-crack $[C(T)]$ and $[S E(B)]$ specimen. Load versus load line displacement were recorded by digital instruments or autographically by $x-y$ plotter. The record of load versus displacement was used to determine crack length. Since Load P, displacement $\mathrm{v}$ and crack length have been estimated at each data point, referring to ASTM E 1820, J could be evaluated to construct J-R curves.

The procedure needs precise specimen preparation and high accuracy instruments to run. The overall J-R curve construction procedure was time consuming and costly. It was also not easy to implement. On the other hand, impact toughness tests evidently could be done at reasonable costs and have been developed for metals and non-metal testing with various purposes easily [4-7]. Some studies have successfully determined J-R curves by applying the normalization method on Charpy Impact test data $[2,8-10]$. The normalization method, which uses the principle of load separation, has been introduced as the convenient way for J-R curve determination. The method related three variables, load $P$, displacement $v$, and crack length during the fracture process, which provides a prediction of any one among three variables from the other two. Using the normalization method, there were many studies that developed further techniques for J-R curve determination in order to overcome some difficult conditions such as: unavailability of crack length, displacement or load measurement $[1,2]$. 
Other studies investigate the possibility to apply a Charpy V-notched (CVN) test to determine fracture toughness $\mathrm{K}_{\mathrm{IC}}$ and critical crack resistance values, JIC [11-13]. Like the previous method, the basic concept of the crack length was proportional to the square of absorbed energy.

Stainless steel is a metallic alloy consisting of at least $10.5 \%$ chromium $(\mathrm{Cr})$ and $50 \%$ iron (Fe). There are various grades of stainless steel such as: Austenitic Stainless Steel, Ferritic Stain less steel, Martensitic stainless steel, duplex stainless steel and precipitation hardening stainless steel. Austenitic Stainless Steel is the most widely used due to its corrosion resistance, mechanical properties and economic value [14]. As, in general, AISI 304 welding potentially faced crack problems, which were considered to be the most serious problems among a variety of physical defects. When there were some cracks in structural components, it could fail at a lower stress level than the ultimate strength of the material [1,2]. Many failures have occurred as a result of fracture, even though the yield stress was not reached.

The main purpose of this study was to apply the previous findings on fracture resistance determination by the Charpy Impact Test to investigate fracture resistance profiles and fracture resistance critical values of American Iron and Steel Institute Standard 304 (AISI 304) welding. Charpy Impact machine equipped with high-speed sampling rate data acquisition equipment is expected to exhibit precisely the relation among the values of energy absorption along the impact test with the presence of chromium interstitial solute and chromium rich carbide precipitation. The relationships were suspected as important keywords in describing fracture resistance profile in each AISI 304 welding zone. When energy absorption along the impact test was increased, it very likely has a strong relationship with obstruction of dislocation movement by the presence of $\mathrm{Cr}$ as a dominant particle in AISI 304, which has a high hardness and yield strength even at high temperature. The formation of chromium carbides and its properties on AISI 304 welding also hamper the movement of dislocation. Both of these obstruction agents were suspected to be the cause of increased energy absorption capability of post welding AISI 304 through the length of Charpy Impact tests, and, finally, influence the fracture resistance profile.

\section{Experimental Method}

AISI 304 strip plate with the dimension of $1000 \mathrm{~mm} \times 100 \mathrm{~mm} \times 10 \mathrm{~mm}$ as shown in Figure 1 was used as a basic material for all necessary testing to investigate the values of AISI 304 welding fracture resistance. Composition of the basic material is presented in Table 1.

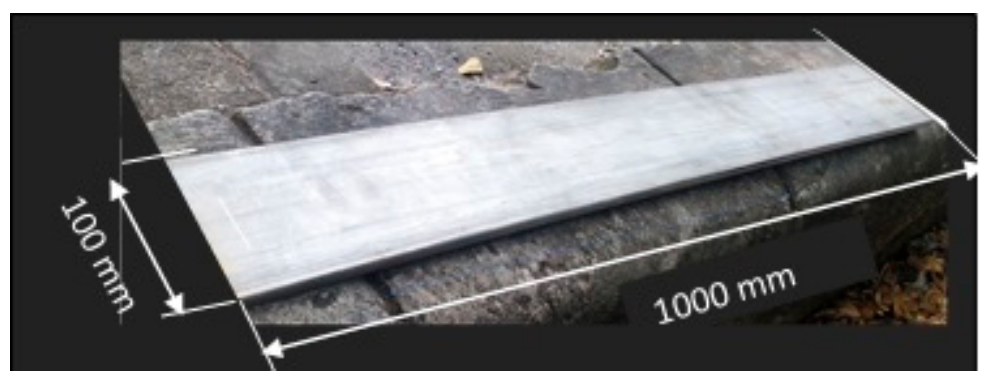

Figure 1. AISI 304 Stainless Steel Strip plate with the dimensions of $1000 \mathrm{~mm} \times 100 \mathrm{~mm} \times 10 \mathrm{~mm}$.

Table 1. Composition of AISI 304.

\begin{tabular}{rcccccccccc}
\hline Element & $\mathbf{C}$ & $\mathbf{C r}$ & $\mathbf{M n}$ & $\mathbf{M o}$ & $\mathbf{N i}$ & $\mathbf{P}$ & $\mathbf{S i}$ & $\mathbf{S}$ & $\mathbf{O}$ & $\mathbf{N}$ \\
\hline Weight $\%$ & 0.041 & 18.4 & 0.19 & 0.19 & 8.5 & 0.031 & 0.54 & 0.014 & 0.025 & 0.062 \\
\hline
\end{tabular}

The material was then welded by TIG with the welding specification as performed in Table 2. 
Table 2. Welding specification.

\begin{tabular}{cl}
\hline Welding Process & 141/Gas Tungsten Arc Welding (GTAW) \\
Welding position & PA/1G-Down hand \\
Joint Type & Butt Joint \\
$\begin{array}{c}\text { Parents Material Specification } \\
\text { Preparation Cleaning }\end{array}$ & AISI 304 \\
& Mechanical \\
& (1) Clean the surface (brush \& grinding); \\
& (2) Dry $50^{\circ} \mathrm{C}$, tack welding \& welding; \\
Welding Sequence & (3) 1 Layer filled weld only in straight layer; \\
& (4) Visual control of welding seam; \\
& (5) Next layer in straight layer \\
& High-Performance Stainless Steel Welding Electro Rod-ER 308 L, \\
& Post drying: dry store, Slow cooling, argon shielding gas \\
Filler Metal & Preheat temp: plate dray $>25^{\circ}$ C, welder's test: welding position European \\
& Standard EN 287-1.PF \\
\hline
\end{tabular}

In order to place the notch precisely in the fusion zones, high temperature heat affected zones, low temperature heat affected zones and unaffected base metals, microstructure observation by optical microscope with a magnification of $100 \times$ was conducted for each zone. The microstructure images of each zone and the distance of notches from the center of welding were shown in Figure $2 \mathrm{a}-\mathrm{d}$, respectively.
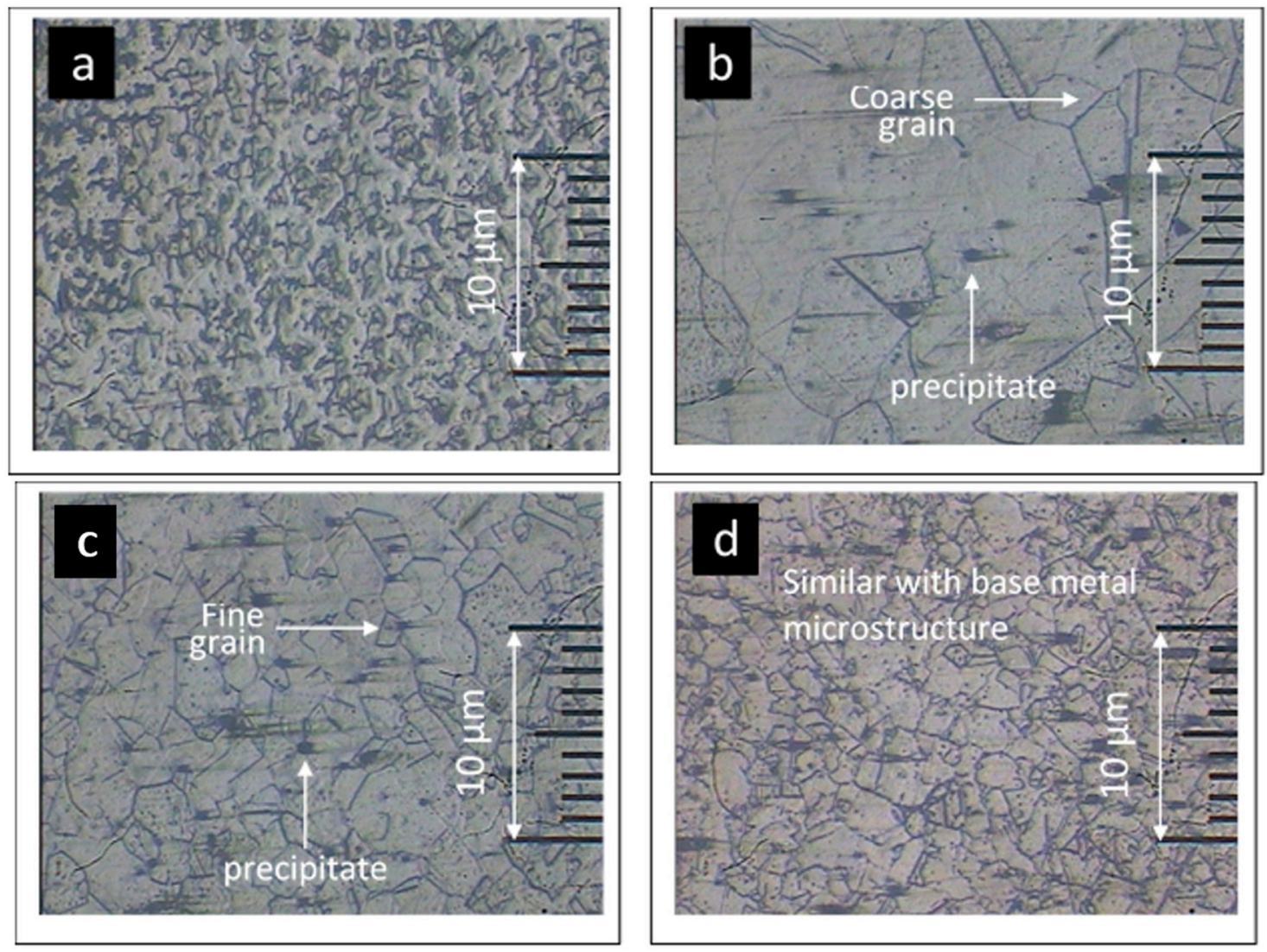

Figure 2. Microstructure of AISI 304 welding. (a) fusion zone, notch position at the center of welding; (b) high temperature heat afected zone, notch position: $4 \mathrm{~mm}$ from the center of welding; (c) low temperature heat affected zone, notch position: $5.5 \mathrm{~mm}$ from the center of welding; (d) unaffected base metal zone notch position: $7 \mathrm{~mm}$ from the center of welding. 
Seven AISI 304 three points bending welded impact specimens for each zone with the dimensions of $55 \mathrm{~mm} \times 10 \mathrm{~mm} \times 10 \mathrm{~mm}$ were prepared using Electrical Discharge Machining (EDM) referring to the ASTM E 23-02a standard [13]. The relative position notch from the center weld bead was presented in Figure 3.

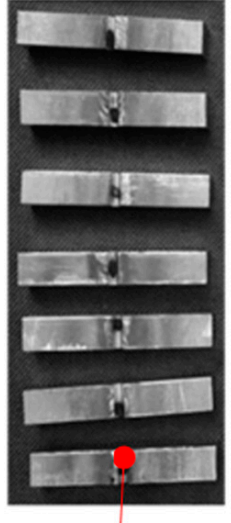

FZ

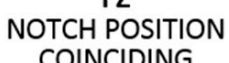

COINCIDING

WITH CENTER

of WELD BEAD

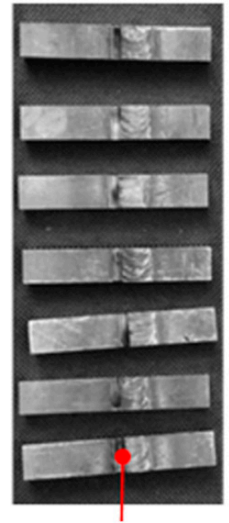

HTHAZ

NOTCH POSITION

$4 \mathrm{~mm}$ from

CENTER of WELD

BEAD

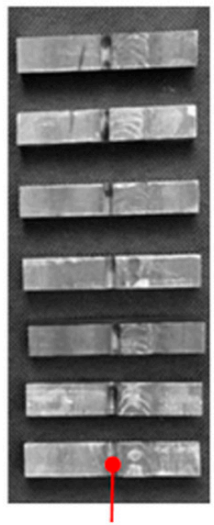

LTHAZ

NOTCH POSITION NOTCH POSITION

$5.5 \mathrm{~mm}$ from $\quad 7 \mathrm{~mm}$ from

CENTER of CENTER of

WELD BEAD WELD BEAD
NOTES:

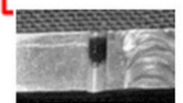

Black/dark part on notches are not welding voids.

There are black color on the

surface which are

resulted in

Electrical

Discharge

Machining

Process

Figure 3. Notch position in an AISI 304 welding Charpy Impact specimen.

Based on ASTM E 23-02a, Charpy Impact tests were conducted with a 300 Joules $\times 2$ Charpy Impact machine equipped with a high-speed sampling rate data acquisition instrument (see Figure 4) in order to examine the energy absorption profile in each zone. The data acquisition instrument (manufactured by Advantech Corporation, Taipei, Taiwan) that consists of a S-type Load Cell, ADAM 3016 signal conditioner, and USB 4702-AE analog to digital converter (ADC) was set to record 45,000 samples per second.

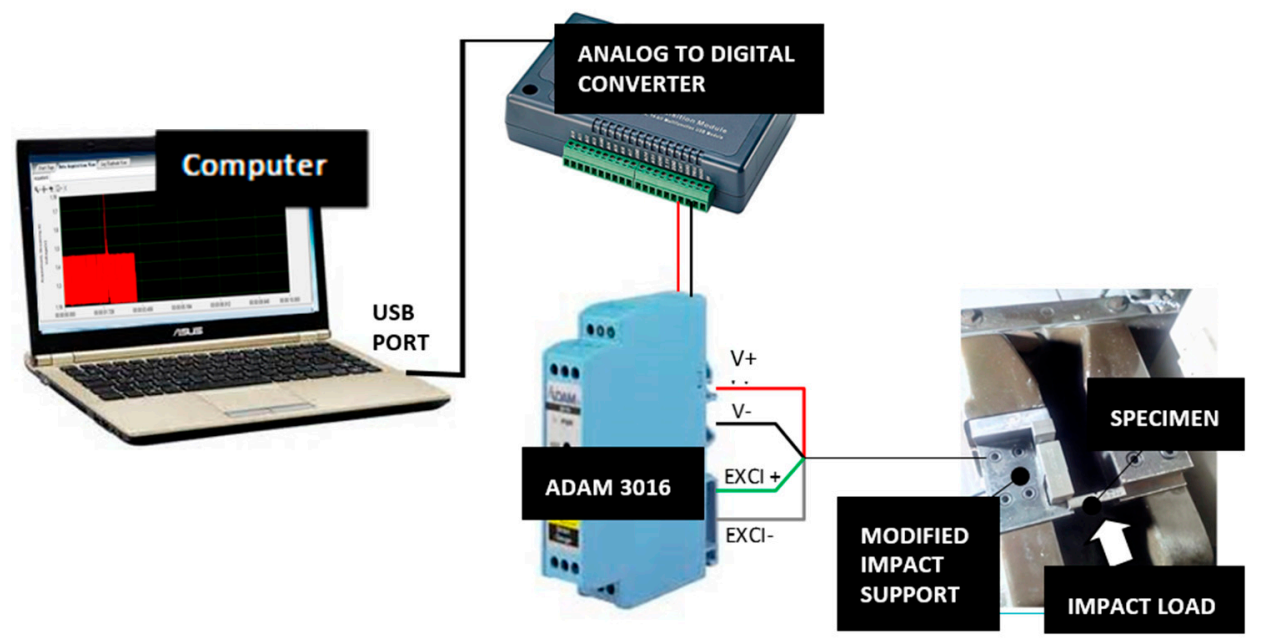

Figure 4. High-speed sampling rate data acquisition instrument.

Fracture surface was observed by a Hitachi SU 3500 Scanning Electron Microscope (Tokyo, Japan) and Energy Dispersive X-ray Spectroscopy, which has the ability to magnify 10-300,000 $\times$ with a depth of field of $4-0.4 \mathrm{~mm}$ and $3 \mathrm{~nm}$ resolution. 


\section{Study Results}

The chart presented in Figure 5 is one of the Charpy Impact test results, representing six other similar results for figures of Charpy Impact tests on seven specimens for each zone.

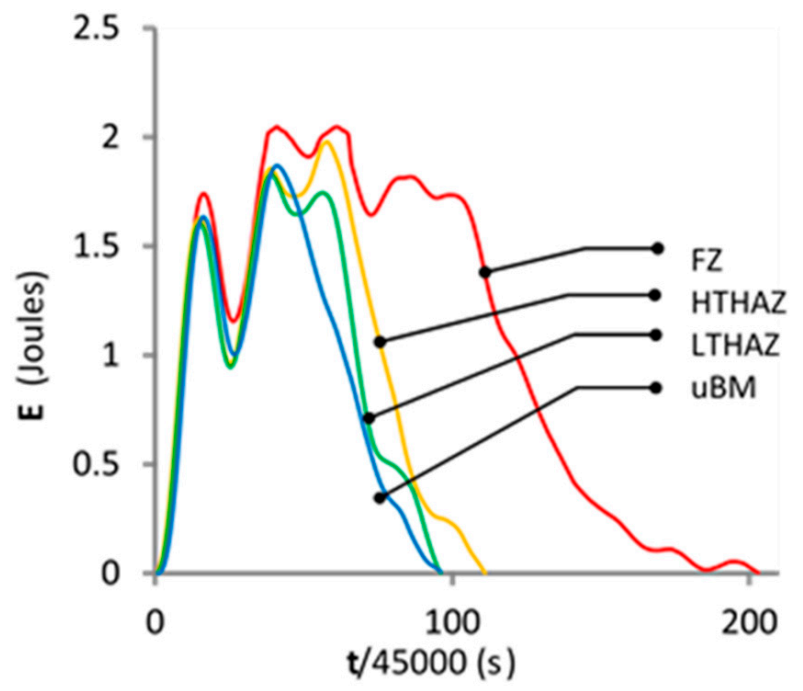

Figure 5. Energy versus unit of time chart for Charpy Impact tests of AISI 304 welding.

The reproducibility of the test was high, considering the resemblance between the test results with Charpy Impact tests conducted with impact velocity of $3.4 \mathrm{~m} / \mathrm{s}$, which was obtained in the previous study by Janssen et al. [15]. Load versus time chart as performed in Figure 5 visually shows that area under the load line, which represents the energy absorbed by the zone during impact loading, is narrower as the distance from the center of welding gets farther. The fusion zone has the ability to absorb the most energy followed by HTHAZ and two other zones, respectively. The load line of LTHAZ and Unaffected Base Metal Zone coincide with each other, which means that they are not significantly different. Total impact energy of each zone could be obtained by estimating the areas under the load line on the chart of each zone and then multiplying by 2 ( 2 support). Impact energy value of each zone was obtained by calculating the area under load line, and impact energy values from the indicator on the impact machine are displayed in Table 3.

Table 3. Impact energy.

\begin{tabular}{ccccc}
\hline \multirow{2}{*}{ Methods } & \multicolumn{4}{c}{ Total Impact Energy (Joules) } \\
\cline { 2 - 5 } & Fusion Zone & HTHAZ & LTHAZ & Unaffected Base Metal \\
\hline Area under load line & 252.9 & 130.9 & 109.9 & 100.36 \\
Indicator on impact machine & 214.8 & 114.5 & 99.5 & 90 \\
\hline
\end{tabular}

Some interesting findings were performed in the load versus time chart as shown in Figure 5 and in the load versus displacement chart in Figure 6a-d. The charts in all of the zones perform a negative overshoot "a", which was occurred typically in the time range of 20 to $30 \mathrm{~ms}$. 

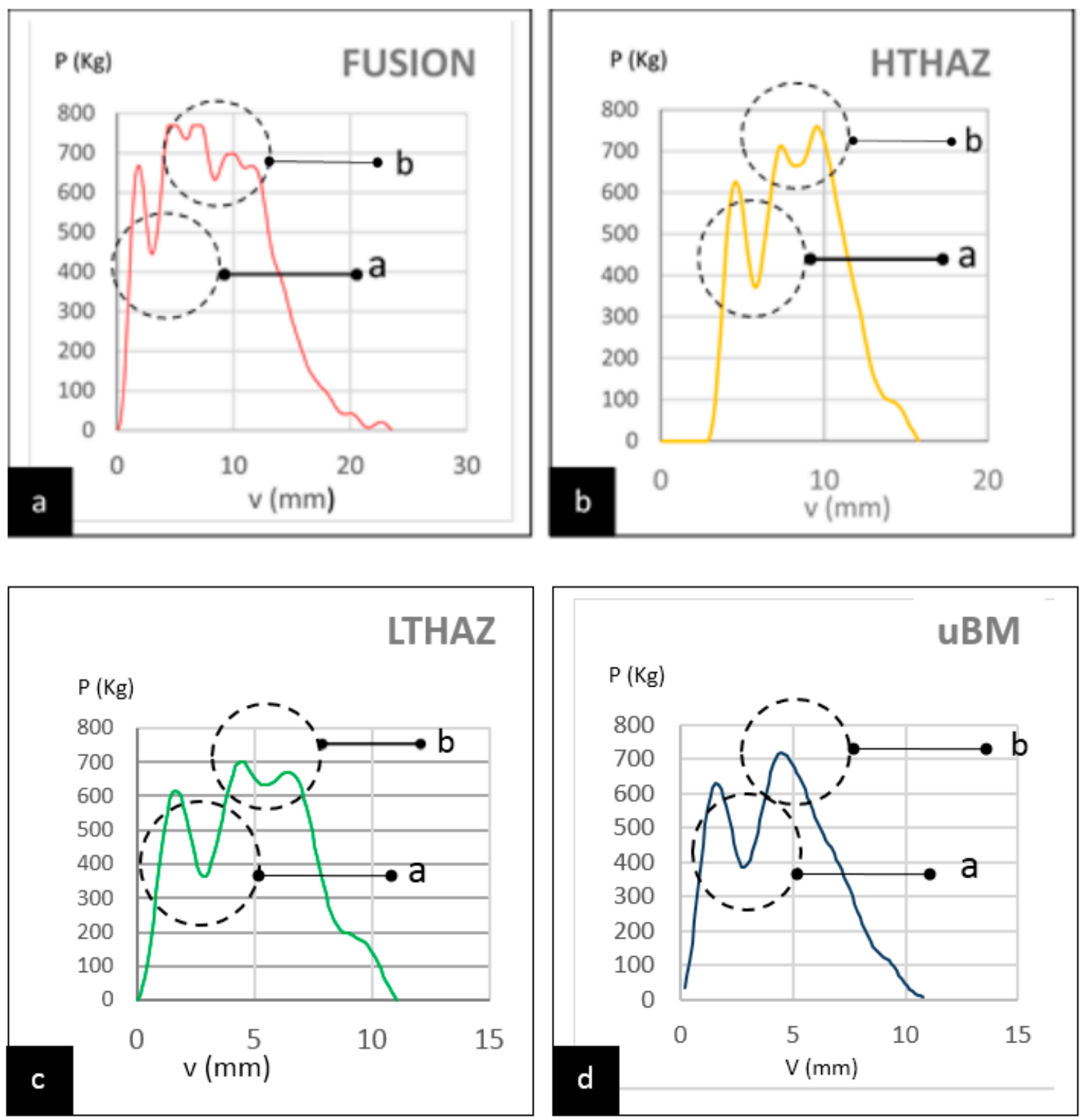

Figure 6. Findings: negative overshoots "a" and number of peaks "b". (a) a negative overshoot "a" and lots of peak " $b$ " in fusion zone (FZ). (b) a negative overshoot " $a$ " and moderate number of peak " $b$ " in high temperature heat affected zone (HTHAZ). (c) a negative overshoot "a" and moderate number of peak " $b$ " in (LTHAZ). (d) a negative overshoot "a" and a peak " $b$ " in unaffected Base Metal (UBM) zone.

The negative overshoot "a" indicates a plastic deformation. Previous research reported that, during plastic deformation, stainless steel 304 transformed into $\alpha^{\prime}$ (bcc) martensite from $\gamma$ (fcc) austenitic. The other study also reported the cold working process, and most of the 300 series stainless steels transform into $\varepsilon$ (hcp) martensite and $\alpha^{\prime}$ (bcc) martensite [16].

The presence of $\mathrm{Cr}$ in this alloy was suspected as a plastic deformation obstruction agent. The dislocation theory could be explained by the Cr atoms' presence dominantly in $\gamma$-Fe- $\mathrm{Ni}$, they would play a role as an interstitial solute, which becomes an obstacle that hampers the motion of dislocation. Once a dislocation has stopped, an extra force was required to make the dislocation move, producing an observed upper loading in a load versus displacement graph. The presence of $\mathrm{Cr}$ atoms can be seen in the image by a Scanning Electron Microscope (SEM) and Energy-dispersive X-ray spectroscopy (EDS) investigation, as shown in Figure 7. 

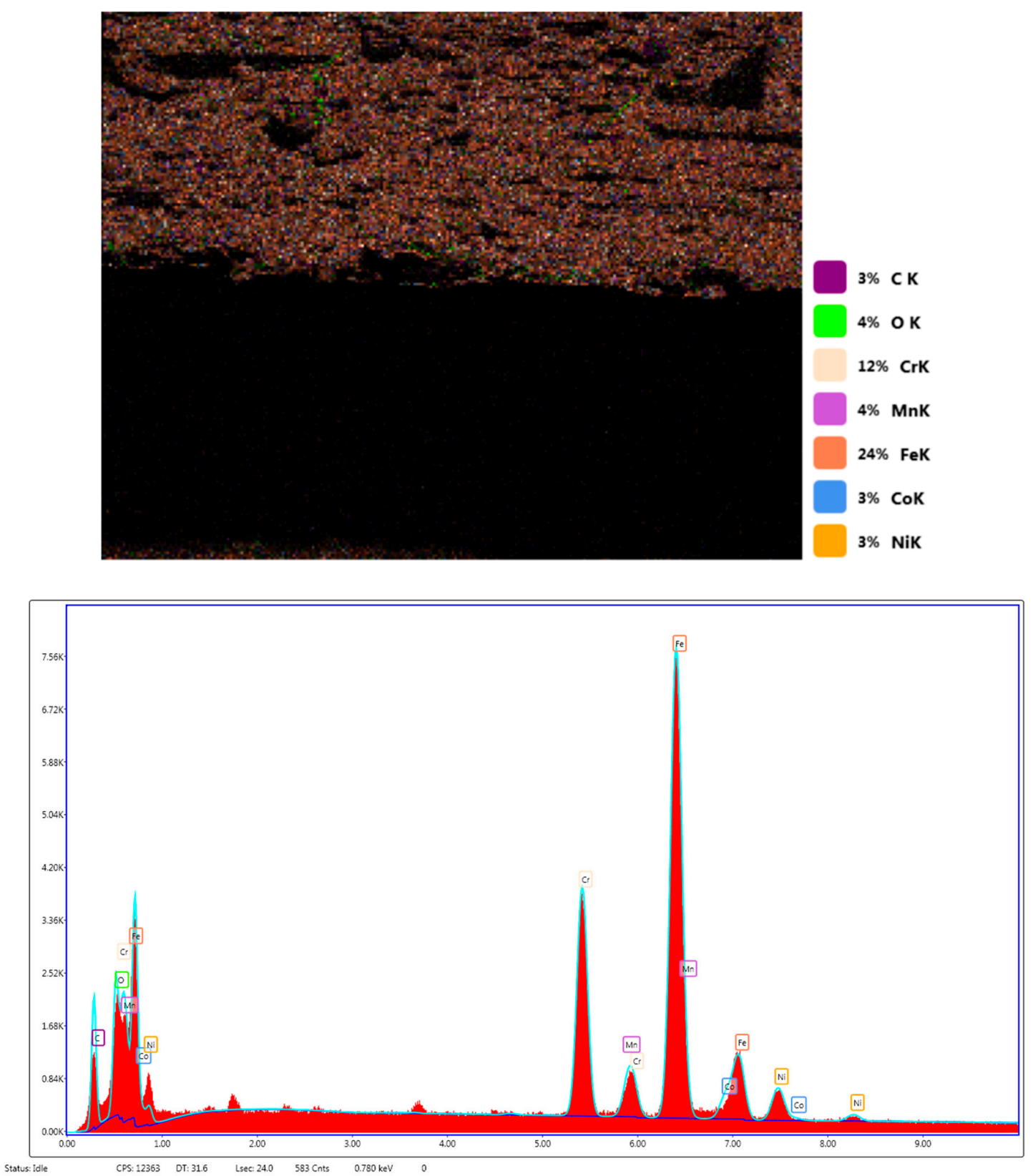

Figure 7. Scanning electron microscope (SEM)/Energy-dispersive X-ray spectroscopy (EDS) investigation indicates the presence of $\mathrm{Cr}$.

The combination of the formation of martensite structure after plastic deformation and the presence of chromium interstisial solute, which has been described above, can be expected to be the main cause of a negative overshoot "a" occurrence.

The numbers of peak " $b$ " variation, which was shown in the previous charts, was another interesting finding. The number of peak decreases as the increase of distance from the center of welding. The number of peaks considered has a relationship with void growth mechanism and the presence of precipitates in austenitic steel welding. Simple austenitic steels contain between $0.03 \%$ and $0.1 \%$ carbon. The solubility limit of carbon is about $0.05 \%$ at $800{ }^{\circ} \mathrm{C}$ up to $0.5 \mathrm{wt} \%$ at $1100{ }^{\circ} \mathrm{C}$. The treatment at the temperature of $1050{ }^{\circ} \mathrm{C}$ to $1150{ }^{\circ} \mathrm{C}$ followed by rapid cooling would produce a solid solution saturated austenite at room temperature. This would lead to rejection of the carbon solid solution at slow cooling or reheating in the range $550-800{ }^{\circ} \mathrm{C}$, even with the carbon content of steel being less than $0.05 \%$. At room temperature, the structure in equilibrium condition contains 
austenite $\gamma, \alpha$ ferrite and carbides [17-19]. Precipitate phase occurred at temperatures below $900{ }^{\circ} \mathrm{C}$. When heated to $1100-1150^{\circ} \mathrm{C}$, carbide went into solution and, on cooling, a precipitate-free austenite was obtained.

When saturated austenite is heated to high temperatures, further precipitation will take place at the austenite grain boundaries. In Stainless steel welding, especially in Heat affected zones, when Stainless steel gained a heating process at more than $300{ }^{\circ} \mathrm{C}$, the process above also takes place. The precipitation in Stainless steel welding, usually called sensitization, was observed by an optical microscope and a Scanning Electron Microscope (SEM). The presence of precipitates with dimensions of about $0.5 \mu \mathrm{m}$ are performed in Figure 8.

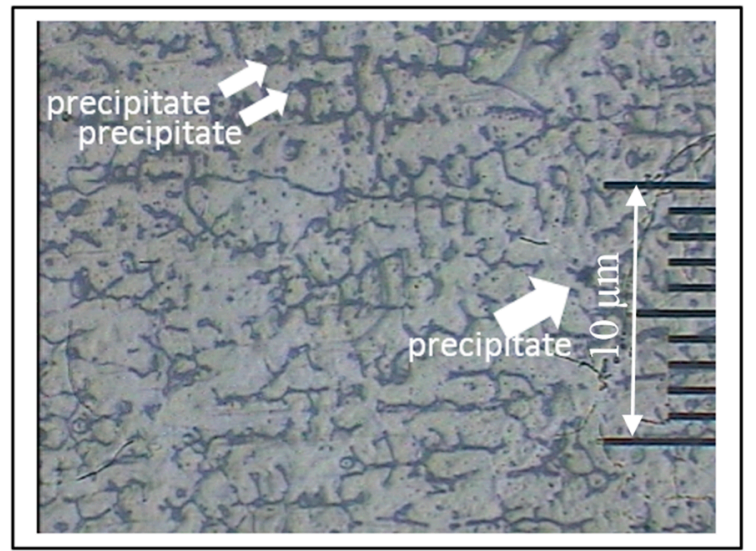

(a)

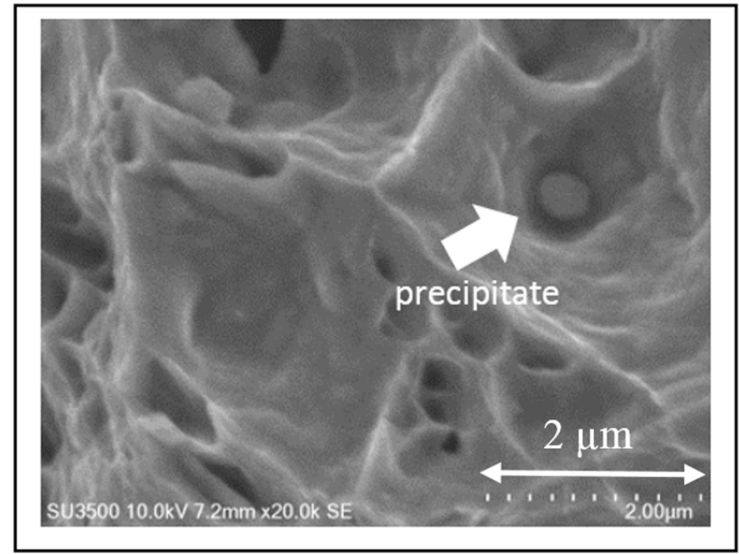

(b)

Figure 8. The presence of precipitates. (a) precipitate observation by optical microscope magnification $=100 ;(\mathbf{b})$ precipitate observation by SEM accelerating voltage $=10,000$ volts; magnification $=20,000$; working distance $=7220 \mu \mathrm{m}$.

The sensitization process results in reduction of chromium content to the weight level of $12 \%$, as displayed in Figure 7, with respect to the origin chromium content at the weight level of $18.4 \%$, as shown in Table 1. This is because the segregated carbon takes up the chromium forming chromium carbides. The dimension of the chromium carbide precipitate corresponded with previous literature, which reported that the precipitate size was varying in the approximated range of $0.5-1.5 \mu \mathrm{m}$ [20]. Energy dispersive X-ray spectroscopy (EDS) was used for compositional point analysis of the precipitates. The EDS results are provided in Figure 9 and Table 4.

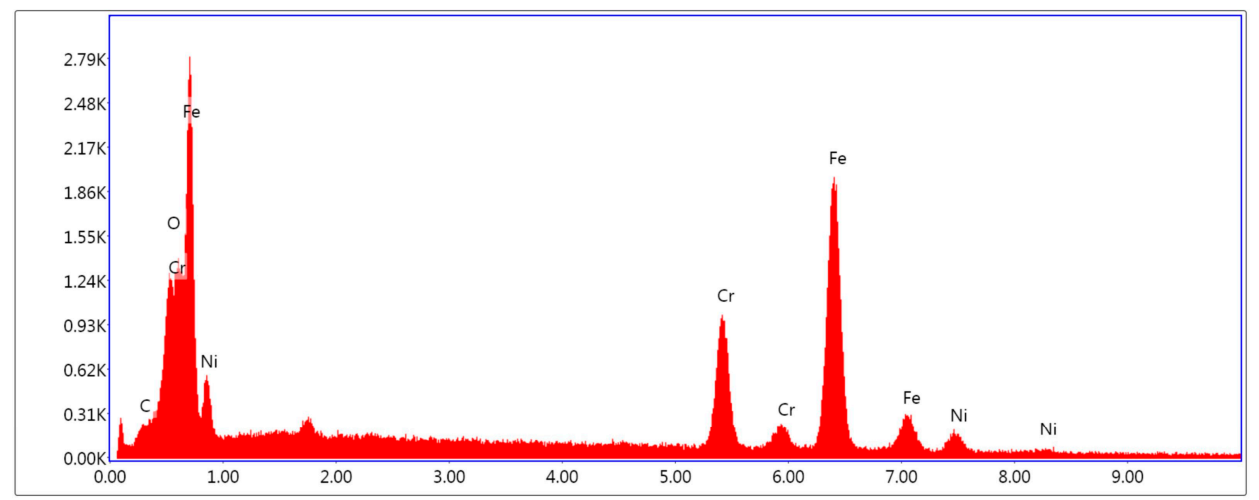

Lsec: 30.00 Cnts 0.000 keV Det: Element-C2 Det

Figure 9. Energy dispersive X-ray spectroscopy (EDS) spectrum of precipitate. 
Table 4. Composition of precipitates.

\begin{tabular}{cccccccccc}
\hline Element & Weight $\%$ & Atomic $\%$ & Net Int. & Error \% & Kratio & Z & R & A & F \\
\hline C K & 5.72 & 20.77 & 117.24 & 10.85 & 0.0202 & 1.3170 & 0.8525 & 0.2677 & 1.0000 \\
O K & 2.53 & 6.90 & 148.64 & 11.45 & 0.0168 & 1.2605 & 0.8775 & 0.5259 & 1.0000 \\
Cr K & 17.37 & 14.57 & 421.19 & 4.46 & 0.2045 & 0.9726 & 1.0013 & 0.9964 & 1.2145 \\
Fe K & 66.70 & 52.07 & 915.48 & 3.39 & 0.6566 & 0.9667 & 1.0094 & 0.9841 & 1.0348 \\
Ni K & 7.67 & 5.69 & 67.14 & 12.08 & 0.0738 & 0.9751 & 1.0145 & 0.9501 & 1.0383 \\
\hline
\end{tabular}

The fracture resistance could not be obtained from the load versus time chart directly. It must be converted to the load versus displacement chart as seen in Figure 6. The conversion could be done by applying a series of calculation methods based on the theory of conventional dynamics [1,2].

Load versus displacement chart could then be analyzed to construct J-R curves, as shown in Figure 10, by predicting the crack length using normalization methods [2].

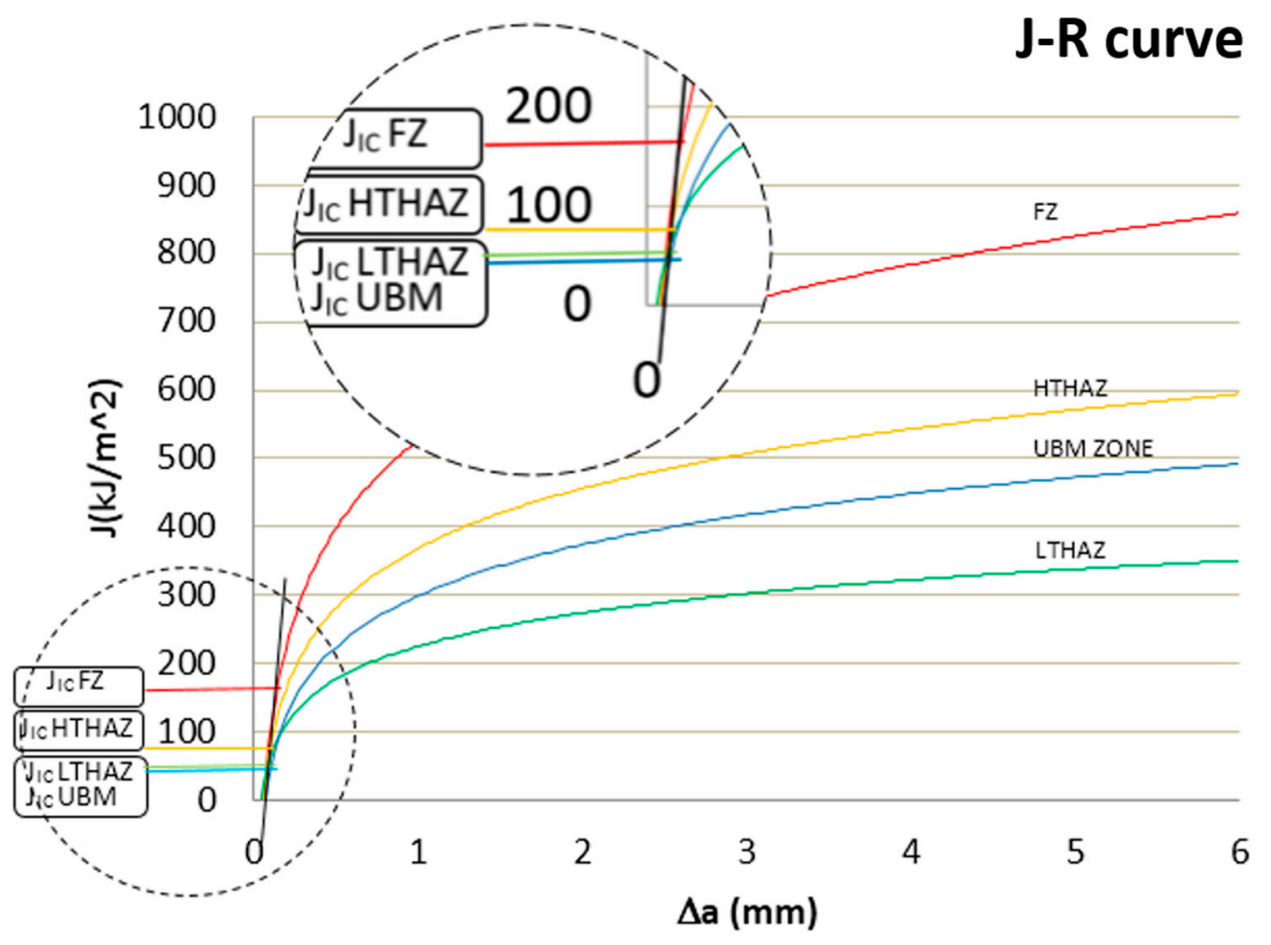

Figure 10. J-R curve of AISI 304 welding.

The fracture resistance profiles were determined by analyzing the fracture resistance curve (R-curve) of each zone. The R-curve in elastic-plastic materials acknowledges the fact that the resistance to fracture increases with growing crack size. The R-curve is a plot of the total energy dissipation rate as a function of the crack size. Figure 10 shows the fracture resistance curve (R-curve) of the Fusion Zone was the highest one, and then followed by HTHAZ, UBM zone and LTHAZ, respectively. The order of R-curve on Figure 10 indicates that fusion zone has the ability to absorb the most energy while LTHAZ has the ability to absorb the least one. The fact was not clearly seen on the energy versus unit of time chart in Charpy Impact test as performed in Figure 5, which made the energy absorption curve on LTHAZ coincide with the energy absorption curve in the UBM zone. The matter is probably due to insignificant precipitate content in LTHAZ. When the temperature is not enough to meet the needs of the sufficient precipitate formation, then precipitate hardening is not evoked adequately in LTHAZ. Unfortunately, the rapid loading on impact test contributes to making the differences of the energy absorption curve as a function of time between LTHAZ and UBM zone less visible. A large amount of energy that is absorbed in the impact process at a medium loading speed will be converted 
into various material responses such as plastic deformation, hysteresis effects, and inertia. The Charpy Impact Specimens receive high-speed loading/rapid loading on impact tests, resulting in a high strain rate. Due to the very high strain rate on the impact test, there is not enough time for the dislocation to move to a grain boundary so that no plastic deformation occurs. The material will suffer transgranular fracture. High strain rate also causes the material to have no chance to maintain its shape. When plastic deformation and inertia effect do not occur due to high strain rate, the material doesn't have an ability to absorb more energy before failure. J-R curve, as performed in Figure 10, displays a more obvious difference regarding the capabilities of LTHAZ and UBM zones in absorbing energy as a function of $\Delta \mathrm{a}$ before failure. The ability of the fusion zone to absorb the most energy indicates that the zone has a better ductility then three other zones. Impact fracture macro image in Figure 11 and scanning electron microscope observation as seen in Figure $8 \mathrm{~b}$ show ductile fracture in fusion zones clearly. The failures by ductile fracture were performed by large and deep dimple rupture. The brittle failure especially in LTHAZ was performed by a smooth surface fracture as seen in Figure 11.
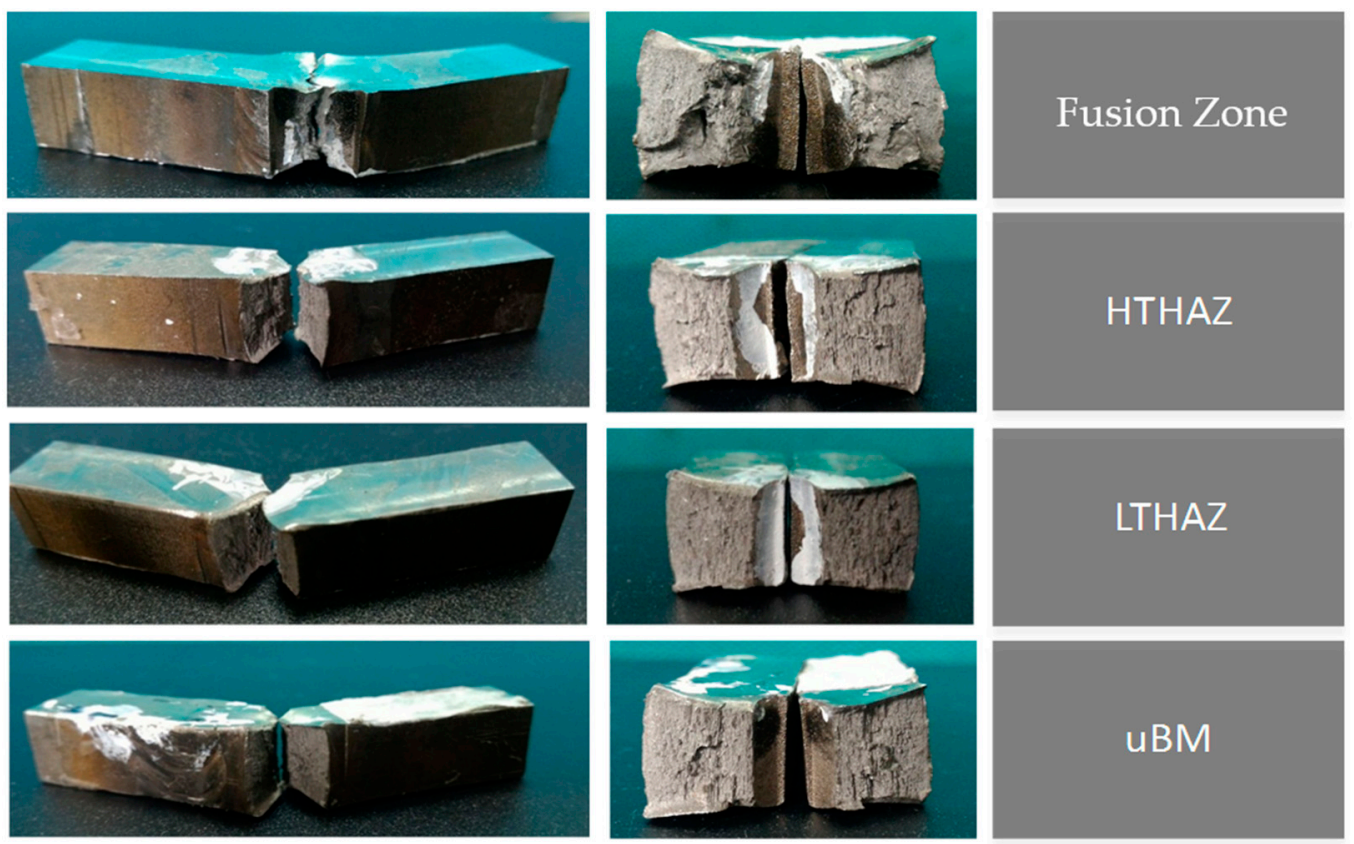

Figure 11. Macro image of impact fracture.

The sequence of R-curves differs from the sequence of critical fracture resistance values (JIC). The JIC values were obtained by graphical projection of intercepts of the R-curve with $0.2 \mathrm{~mm}$ offset line horizontally to the ordinate axis. Critical fracture resistance value $\left(\mathrm{J}_{\mathrm{IC}}\right)$ of the UBM zone was the lowest one, which is not significantly different from the Critical fracture resistance value of LTHAZ.

When the values of fracture toughness $\mathrm{K}_{\mathrm{IC}}$ could be obtained by using the relation with the Charpy V-Notch test result (CVN), as mentioned in the introduction and shown in Table 5 adapted from reference [11], then critical values of fracture resistance $\mathrm{J}_{\text {IC }}$ is determined by [3]:

$$
\mathrm{K}_{\mathrm{IC}}=\sqrt{\mathrm{EJ}_{\mathrm{IC}}},
$$

where $\mathrm{K}_{\mathrm{IC}}$ is critical fracture toughness value ; $\mathrm{E}$ is Young modulus for plane stress condition and $\mathrm{J}_{\mathrm{IC}}$ is a critical fracture resistance value. 
Table 5. Relationship between $\mathrm{K}_{\mathrm{IC}}-\mathrm{CVN}$ (Source: Terán et al., [11]).

\begin{tabular}{ccc}
\hline Formula & Units & Equation Number \\
\hline Rolfe-Novak-Barson $\left[\left(\frac{\mathrm{K}_{\mathrm{IC}}}{\sigma_{\mathrm{ys}}}\right)^{2}=0.64\left(\frac{\mathrm{CVN}}{\sigma_{\mathrm{ys}}}-0.01\right)\right]$ & $\mathrm{Mpa} \sqrt{m}, \mathrm{Mpa}, \mathrm{J}$ & (2) \\
Welding Research Council $(\mathrm{WRC}) 265$ & $\mathrm{Mpa} \sqrt{m}, \mathrm{Mpa}, \mathrm{J}$ \\
{$\left[\left(\frac{\mathrm{K}_{\mathrm{IC}}}{\sigma_{\mathrm{ys}}}\right)^{2}=0.54\left(\frac{\mathrm{CVN}}{\sigma_{\mathrm{ys}}}-0.02\right)\right]$} & $\mathrm{Mpa} \sqrt{m}, \mathrm{Mpa}, \mathrm{J}$ \\
Robert and Newton $\left[\mathrm{K}_{\mathrm{IC}}=0.804 \sigma_{\mathrm{ys}}\left(\frac{\mathrm{CVN}}{\sigma_{\mathrm{ys}}}-0.0098\right)^{0.5}\right]$ & $\mathrm{Mpa} \sqrt{m}, \mathrm{Mpa}, \mathrm{J}$ \\
Sailors and Corten $\left[\mathrm{K}_{\mathrm{IC}}=14.6(\mathrm{CVN})^{0.50}\right]$ & $\mathrm{Mpa} \sqrt{m}, \mathrm{Mpa}, \mathrm{J}$ & $(4)$ \\
Marandet and Sanz $\left[\mathrm{K}_{\mathrm{IC}}=19(\mathrm{CVN})^{0.50}\right]$ & $\mathrm{Mpa} \sqrt{m}, \mathrm{~J}$ & $(6)$ \\
Materials Standard Institution, Stockholm & \\
INSTA $\left[\mathrm{K}_{\mathrm{IC}}=12 \sqrt{\mathrm{CVN}]}\right.$ & \\
\hline
\end{tabular}

The values of fracture toughness $\mathrm{K}_{\mathrm{IC}}$ resulting from the calculation using the relationships shown in Table 5 and calculated $\mathrm{JIC}_{\mathrm{IC}}$ using Equation (1) are performed in Table 6.

Table 6. Calculated $\mathrm{K}_{\mathrm{IC}}$ by various formulas.

\begin{tabular}{ccccccccc}
\hline \multirow{2}{*}{ Formula } & \multicolumn{2}{c}{ FZ } & \multicolumn{2}{c}{ HTHAZ } & \multicolumn{2}{c}{ LTHAZ } & \multicolumn{2}{c}{ UBM } \\
\cline { 2 - 9 } & K IC & J IC & K IC & JIC & K IC & J IC & K $_{\text {IC }}$ & J IC \\
\hline Rolfe-Novak-Barson & 185.750 & 172.516 & 133.101 & 88.58 & 121.763 & 74.132 & 116.248 & 67.568 \\
Welding Research & 169.889 & 144.312 & 121.236 & 73.491 & 110.725 & 61.301 & 105.605 & 55.763 \\
Council (WRC) 265 & & & & & & & \\
Robert and Newton & 174.275 & 151.859 & 89.497 & 40.049 & 74.905 & 28.054 & 68.275 & 23.308 \\
Sailors and Corten & 269.540 & 363.261 & 139.513 & 97.319 & 117.131 & 68.598 & 106.963 & 57.206 \\
Marandet and Sanz & 456.484 & 1041.89 & 236.274 & 279.128 & 198.369 & 196.752 & 181.149 & 164.076 \\
INSTA & 182.088 & 165.780 & 94.248 & 44.413 & 79.128 & 31.306 & 72.259 & 26.107 \\
\hline
\end{tabular}

The critical values of fracture resistance $\left(\mathrm{J}_{\mathrm{IC}}\right)$ of the fusion zone estimated from the graphical procedure is $170 \mathrm{~kJ} / \mathrm{m}^{2}$ followed by HTHAZ with critical fracture resistance value of $85 \mathrm{~kJ} / \mathrm{m}^{2}$ and two other zones, LTHAZ and UBM, with similar critical fracture resistance values of approximately $60 \mathrm{~kJ} / \mathrm{m}^{2}$ and $50 \mathrm{~kJ} / \mathrm{m}^{2}$, respectively.

The most corresponding critical fracture resistance values on the comparison list in all zones by both methods is provided in Table 7 as follows:

Table 7. The critical fracture resistance (JIC) comparison list.

\begin{tabular}{ccccc}
\hline Methods & FZ $\left.\mathbf{( k J} / \mathbf{m}^{\mathbf{2}}\right)$ & HTHAZ $\left.\mathbf{( k J} / \mathbf{m}^{\mathbf{2}}\right)$ & LTHAZ $\left.\mathbf{( k J} / \mathbf{m}^{\mathbf{2}}\right)$ & UBM $\left(\mathbf{k J} / \mathbf{m}^{\mathbf{2}}\right)$ \\
\hline Graphical methods & 170 & 85 & 60 & 50 \\
\hline $\begin{array}{c}\text { The most corresponding } \\
\text { calculated values }\end{array}$ & 172.516 & 88.58 & 61.301 & 55.763 \\
\hline
\end{tabular}

The critical fracture resistance values $\left(\mathrm{J}_{\mathrm{IC}}\right.$ ) of all zones were obtained by the graphical methods are looked similar with the JIC values which calculated by the formula of Rolve-Novak-Barson. The similar critical fracture resistance values relates to the fit between AISI 304 yield stress of $215 \mathrm{MPa}$ with Rolve-Novak-Barson material yield stress usage restrictions in the range of 170-760.

\section{Discussion}

The critical values of fracture resistance by both methods were strongly associated with the previous findings of chromium interstitial solute (see Figure 7), which was allegedly responsible for strengthening the material. Strength of the material depends on the material's ability to resist the movement of the dislocation. Dislocations generate a stress that will interact with local stresses formed by the presence of chromium as solute atoms. When dislocation movement was inhibited, 
the magnitude of shear stress required moving dislocations in a material is greater, causing an increase in the yield stress of the material, which also means an increase in strength of the material. The solid solution strengthening depends on a concentration of the solute atoms, modulus of the solute atoms, size of the solute atoms, valence of the solute atoms, and the symmetry of the solute field [21,22]. In the present study, the critical values of fracture resistance are also related with chromium rich carbide precipitation, which was already outlined in the previous section. The energy versus unit of time chart in Figure 5 shows that the fusion zone as a zone with the highest number of peak " $b$ " has an ability to absorb energy more than other zones. As mentioned in the previous section, the number of peaks on the graph considered have a relationship with the presence of precipitates in the zone. In most binary systems, the second phase will be formed when the concentration of alloy is above the concentration given by the phase diagram. The alloy in the the form of the second phase in the solid solution at elevated temperatures becomes precipitate upon quenching and aging at lower temperature The precipitate has an important role in strengthening mechanism of alloy, which is called precipitation hardening [22,23]. The precipitate particle acts as a barrier to dislocation in several ways. If the precipitate atoms' radii are small, the dislocations will cut through the precipitate. As a result, new surfaces get exposed to the matrix and lead the increasing of the particle-matrix interfacial energy. As the size of the second phase particle increases, it becomes increasingly difficult for the particles to cut through the material. Hence, dislocations tend to loop/to bow around the particle by Orowan Looping. At a critical diameter of about $10 \mathrm{~nm}-60 \mathrm{~nm}$, dislocations will preferably cut across the obstacle, while, for a diameter more than $60 \mathrm{~nm}$, the dislocations will readily loop or bow to overcome the obstacle. The precipitate with the small size (up to $0.05 \mu \mathrm{m}$ ) and intermediate size $(0.05-0.5 \mu \mathrm{m})$ makes a contribution to strengthening the stainless steel by improving hardness and yield strength [3]. When the precipitate in austenite boundaries is getting coarse, then it can easily become a void nucleation site or crack $[23,24]$. In the present study, a few and less dominant large precipitates appeared as shown in Figure 12.

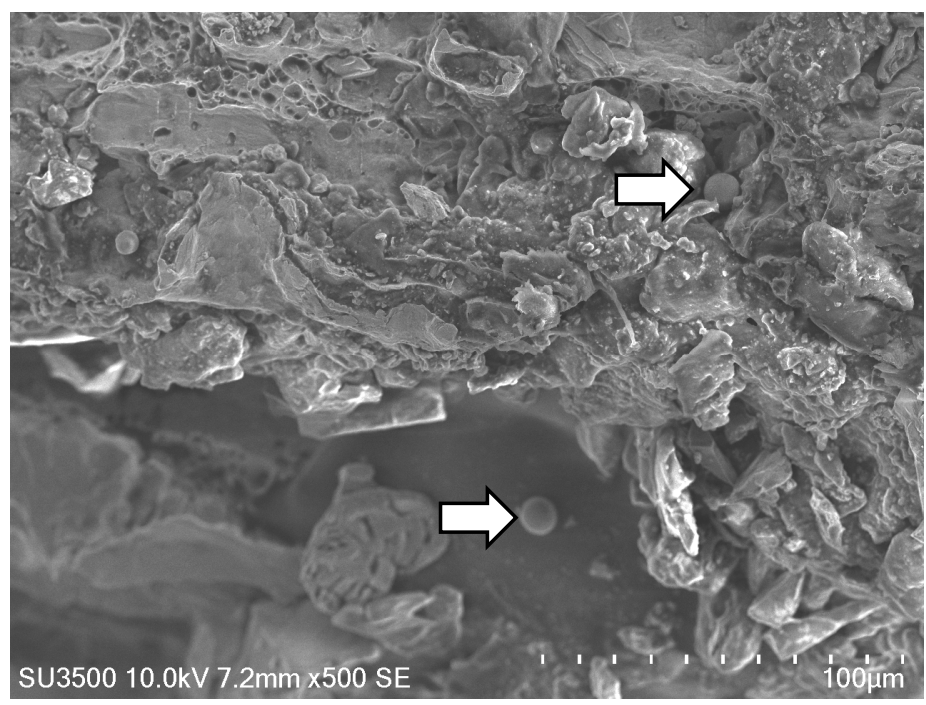

Figure 12. The presence of less dominant large precipitate.

Impact fracture surface images are performed in Figure 13. Void growth mechanism on the fusion zone is dominant in the stable crack extension region as indicated with very large dimples with size of about $2 \mu \mathrm{m}$. The dimples are less and shallower in other zones, as shown in Figure 13b-d, indicating a more brittle material.

High stress triaxiality (plane-strain state) is suspected as triggering fast void growth, leading to formation of large dimples [25]. 


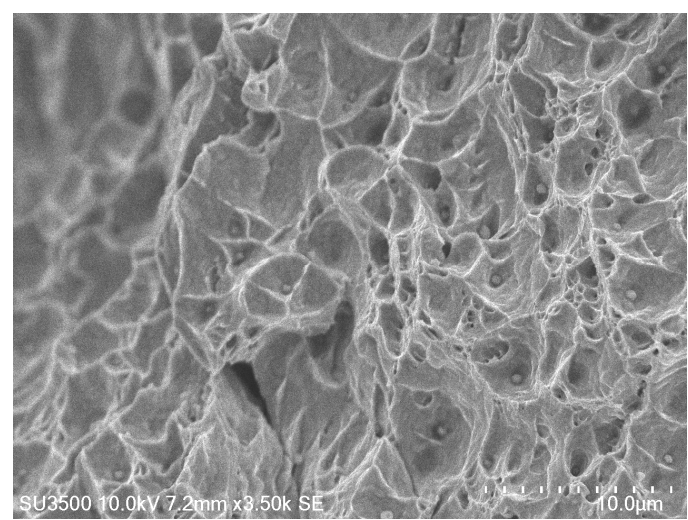

(a)

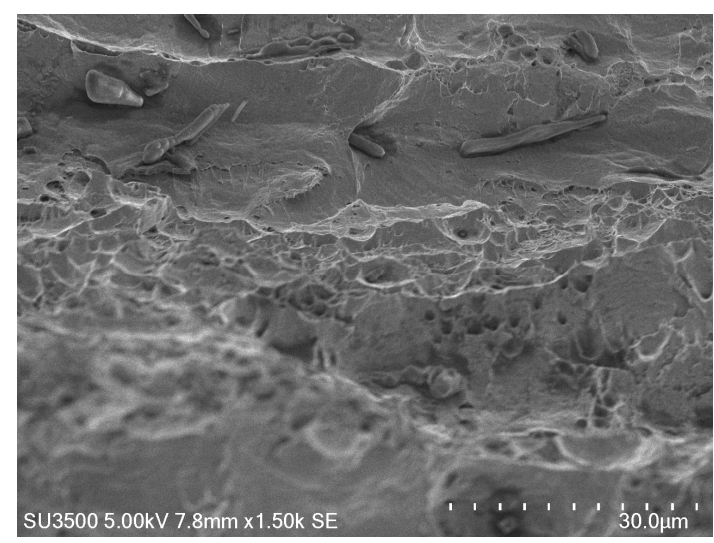

(c)

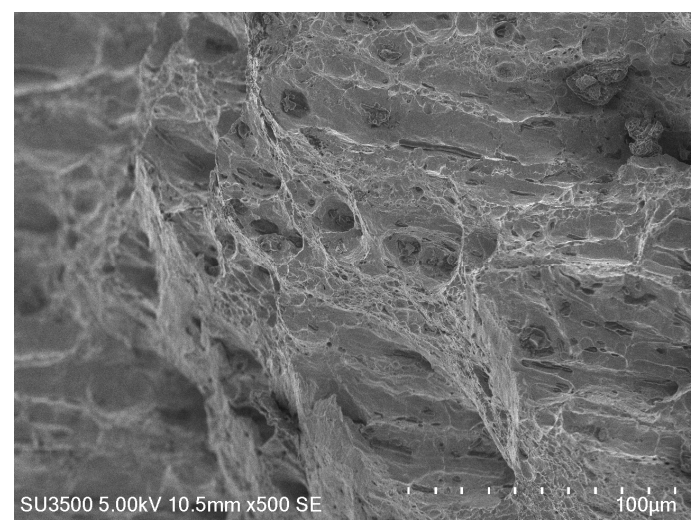

(b)

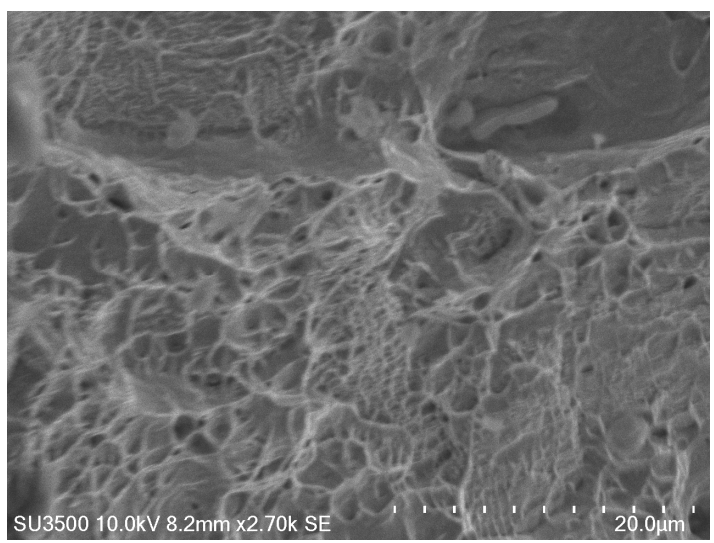

(d)

Figure 13. Scanning electron microscope of impact fracture surface. (a) fusion zone accelerating voltage $=10,000$ Volt; magnification $=3500$; working distance $=7210 \mu \mathrm{m} ;(\mathbf{b})$ high temperature heat affected zone accelerating voltage $=5000$ volts; magnification $=500$; working distance $=1030 \mu \mathrm{m}$; (c) low temperature heat affected zone accelerating voltage $=5000$ volts; magnification $=1500$; working distance $=7820 \mu \mathrm{m} ;(\mathbf{d})$ unaffected base metal accelerating voltage $=10,000$ volts; magnification $=2700$; working distance $=8190 \mu \mathrm{m}$.

\section{Conclusions}

The study succesfully performed the fracture resistance chart (J-R curve) of AISI 304 welding by a high speed sampling rate Charpy Impact Test. The R-curve of the Fusion Zone was the highest one, then followed by HTHAZ, the UBM zone and LTHAZ, respectively. The sequence of R curves differs from the sequence of critical fracture resistance values $\left(\mathrm{J}_{\mathrm{IC}}\right)$, and critical fracture resistance value of the Fusion Zone was highest followed by HTHAZ, LTHAZ and UBM, respectively. Compared with energy vs. unit time graph, the J-R curve chart has advantages in displaying a more obvious difference in the capabilities of the zones in absorbing energy before failure, especially between LTHAZ and UBM zones.

The present study also found the presence of $\mathrm{Cr}$ in all zones, which act as a plastic deformation obstruction agent, showed on the impact graph as a negative overshoot followed by increasing energy absorption. The increase of energy absorption capability, due to dislocation obstruction by the presence of a hard and strong $\mathrm{Cr}$ atom as a dominant particle, increases the fracture resistance profile of AISI 304. The observation throughout the impact test also showed a fine chromium carbide precipitate particle in an elevated temperature zone during the welding act as a barrier to dislocation, strengthening the AISI 304 and eventually influencing the fracture resistance profile, especially on fusion zones. 
Acknowledgments: The authors gratefully acknowledge support from the Government of the Republic Indonesia for providing the fellowships and financial support, which made the program possible. Any kind of support from Universitas Muhammadiyah Yogyakarta are also acknowledged.

Author Contributions: Bambang Riyanta, I. N. G. Wardana, Yudy Surya Irawan and Moch. Agus Choiron conceived and designed the experiments; Bambang Riyanta performed the experiments; Bambang Riyanta analyzed the data; Bambang Riyanta contributed reagents/materials/analysis tools; Bambang Riyanta, I. N. G. Wardana, Yudy Surya Irawan and Moch. Agus Choiron wrote the paper.

Conflicts of Interest: The authors declare that there is no conflict of interest in the manuscript.

\section{References}

1. Brandon, P.P. Fracture Toughness: Evaluation of Testing Procedure to Simplify JIc Calculations. Master's Thesis, University of Tennessee, Knoxville, TN, USA, May 2005.

2. Lee, K. Elastic-Plastic Fracture Toughness Determination under Some Difficult Conditions. Ph.D. Thesis, University of Tennessee, Knoxville, TN, USA, August 1995.

3. Broek, D. Elementary Engineering Fracture Mechanics, 4th ed.; Kluwer Academic Publishers: Dordrecht, The Netherlands, 1986.

4. Zhang, X.; Gao, H. A Study of Impact Toughness of Intercritically Reheated Coarsed-Grain of Heat Effected Zone of Two Type X80 Grade Pipeline Steel; Spesial Issue on WSE2011; Transaction of JWRI: Osaka, Japan, 2011.

5. Purnomo, P.; Soenoko, R.; Suprapto, A.; Irawan, Y.S. Impact Fracture Toughness Evaluation by Essential Work of Fracture Method in High Density Polyethylene Filled with Zeolite. FME Trans. 2016, 44, 180-186. [CrossRef]

6. Kim, H.; Kang, M.; Jung, H.J.; Kim, H.S.; Bae, C.M.; Lee, S. Mechanisms of toughness improvement in Charpy impact and fracture toughness tests of non-heat-treating cold-drawn steelbar. Mater. Sci. Eng. 2013, 571, 38-48. [CrossRef]

7. Pamnania, R.; Jayakumarb, T.; Vasudevanb, M.; Sakthivelb, T. Investigations on the impact toughness of HSLA steel arc welded joints. J. Manuf. Process. 2016, 21, 75-86. [CrossRef]

8. Landes, J.D.; Zhou, Z.; Lee, K.; Herrera, R. Normalization Method for Developing J-R Curves with the LMN function. J. Test. Eval. 1991, 19, 305-311.

9. Lee, K.; Landes, J.D. Developing J-R Curves without Displacement Measurement Using Normalization. In Fracture Mechanics: Twenty-Third Symposium; Chona, R., Ed.; ASTM International: Philadelphia, PA, USA, 1993; pp. 133-167.

10. Chaouadi, R.; Puzzolante, J.L. Crack resistance determination from the charpy impact test. In Proceedings of the 16th European Conference of Fracture, Alexandroupolis, Greece, 3-7 July 2006; pp. 515-516.

11. Terán, G.; Colindres, S.C.; Herrera, D.A.; Velázquez, J.C.; Cueto, F.M. Estimation of fracture toughness KIC from Charpy impact test data in T-welded connections repaired by grinding and wet welding. Eng. Fract. Mech. 2016, 153, 351-359. [CrossRef]

12. Kapp, J.A.; Underwood, J.H. Correlation between Fracture Toughness, Charpy V-Notch Impact Energy, and Yield Strength for ASTM A723 Steel; Technical Report, ARCCB-MR-92008; U.S. Army Ardec Benet Laboratories: Watervliet, NY, USA, 1992.

13. ASTM E23-02. Standard Test Methods for Notched Bar Impact Testing of Metallic Materials; ASTM Committee E28: West Conshohocken, PA, USA, May 2005.

14. McGuire, M.F. Stainless Steels for Design Engineers, 1st ed.; ASM International: Geauga County, OH, USA, 2008.

15. Janssen, M.; van Leeuwen, M.B.; de Leon Mendes, M.F. Fracture Toughness of High-Chromium White Cast Iron in Relation to the Primary Carbide Morphology. In Proceedings of the 13th European Conference on Fracture, San Sebastian, Spain, 6-9 September 2000.

16. Ding, Y. Effects of Elevated Temperature Exposure on the Microstructural Evolution of $\mathrm{Ni}(\mathrm{Cr})-\mathrm{Cr} 3 \mathrm{C} 2 \mathrm{Coated}$ 304 Stainless Steel. Ph.D. Thesis, University of Nottingham, Nottingham, UK, June 2009.

17. Young, S.Y. Thermodynamic Study on B and Fe Substituted Cr23C6 Using First-Principles Calculations. Master's Thesis, Pohang University of Science and Technology, Pohang, Korea, 15 April 2010.

18. Fujita, N. Modelling Carbide Precipitation in Alloy Steels. Ph.D. Thesis, University of Cambridge, Cambridge, UK, February 2000.

19. Bhadeshia, H.K. Design of Ferritic Creep-resistant Steels. ISIJ Int. 2001, 41, 626-640. [CrossRef] 
20. Gharehbaghi, A. Precipitation Study in a High Temperature Austenitic Stainless Steel Using Low Voltage Energy Dispersive X-ray Spectroscopy. Master's Thesis, Royal Institute of Technology, Stockholm, Sweden, March 2012.

21. Joshua, P. Mechanical Properties of Materials; Springer: New York, NY, USA, 2013; pp. 236-239, ISBN 978-94-007-4341-0.

22. Dieter, G.E. Mechanical Metallurgy; McGraw-Hill Publishing Company: New York, NY, USA, 1986.

23. Callister, W.D. Fundamentals of Materials Science and Engineering, 2nd ed.; Wiley \& Sons: Hoboken, NJ, USA, 2004.

24. Thosmas, H.C. Mechanical Behavior of Materials, 2nd ed.; Waveland Press, Inc.: Long Grove, IL, USA, 2005.

25. Chen, J.; Verreman, Y.; Lanteigne, J. On fracture toughness JIC testing of martensitic Stainless Steels. In Proceedings of the13th International Conference on Fracture, Beijing, China, 16-21 June 2013.

(C) 2017 by the authors. Licensee MDPI, Basel, Switzerland. This article is an open access article distributed under the terms and conditions of the Creative Commons Attribution (CC BY) license (http:/ / creativecommons.org/licenses/by/4.0/). 